\title{
Surface-modified Water Hyacinth (Eichhornia crassipes) over Activated Carbon for Wastewater Treatment: A Comparative Account
}

\author{
Shreyas A. Bapat ${ }^{(1 D \S}$ and Dipika K. Jaspal, ${ }^{\mathrm{b} *} \mathbb{D}$ \\ Symbiosis Institute of Technology (SIT), Symbiosis International (Deemed University) (SIU), Gram: Lavale, \\ Tal: Mulshi, Pune-412115, Maharashtra, India.
}

Received 13 November 2019, revised 10 December 2019, accepted 8 March 2020

\begin{abstract}
Finding an economical, efficient and easy handling alternative for commercial grade activated charcoal (AC) in textile wastewater treatment is a dire need. To address this, a noxious weed water hyacinth (WH) has been explored as a 'biosorbent' for the decolorization of the hazardous textile dye, Remazol Brilliant Red 3BS (RBR 3BS) in wastewater. A novel surface modification has been carried out using the quaternary ammonium salt, N-Cetyl-N,N,N-trimethyl ammonium bromide, to enhance the dye decolorization capacity of raw WH. The impact of several process parameters, viz. $\mathrm{pH}$, dosage of adsorbent, temperature, concentration and contact time have been examined. Batch adsorption studies, kinetic-thermodynamics, isothermal modelling and error analysis have been studied to ascertain the efficacy of the adsorbent. A comparison of the results has been carried out with activated carbon (AC). Surface-modified WH showed the highest dye uptake of $104.26 \mathrm{mg} \mathrm{g}^{-1}$, at $27^{\circ} \mathrm{C}$, which was about 10 times more than that of AC. Isothermal, kinetic and thermodynamic studies were conducted for identification of adsorption type taking place for dye-adsorbent systems. Energy of activation was $8.65 \mathrm{~kJ} \mathrm{~mol}^{-1}$ for treated $\mathrm{WH}$ and $8.98 \mathrm{~kJ} \mathrm{~mol}^{-1}$ for AC. It was proven that surface-modified WH had a high capability to replace AC for adsorption treatments.
\end{abstract}

KEYWORDS

Textile dye, adsorption, surface modification, water hyacinth, activated charcoal.

\section{Introduction}

Clean water is a finite natural resource, which needs to be sustained for future generations. Industries around the world produce toxic substances as by-products, which are let into water bodies, thereby polluting the water resources. The significant contaminants include chemicals and dyes from textile, paint-pigment, battery manufacturing, tannery and pharmaceutical industries. ${ }^{1-5}$

Textile industries use a variety of dyes, viz. mordent, sulphur, vat, azo, reactive, acidic and basic dyes. ${ }^{6}$ The toxicity, complex chemical behaviour and non-biodegradability of these dyes makes their removal difficult, posing an environmental threat. ${ }^{7}$ Remazol Brilliant Red 3BS (RBR 3BS) is one such commercial textile dye, which is known to cause respiratory irritation and skin allergies in humans. It is also toxic (MSDS, RBR 3BS, Dystar Ltd.) for the aquatic environment ${ }^{8,9}$

For many years, the need for efficient methods for the complete elimination of these dyes has been a challenge for ecologists and scientists. Various methods for dye removal from wastewater have been investigated and reported in literature. These include froth flotation, ${ }^{10}$ precipitation, ${ }^{11}$ flocculationcoagulation, ${ }^{12}$ reverse osmosis, ${ }^{13}$ membrane filtration, ${ }^{14}$ photo degradation, ${ }^{15}$ electro-chemical destruction, ${ }^{16}$ irradiationozonization, 17,18 Zn-Ferrite inorganic catalyst-assisted photo Fenton degradation, ${ }^{19}$ adsorption using nanoparticles derived from tea extract ${ }^{20}$ and adsorption using commercial grade activated charcoal (AC). ${ }^{21}$

Out of the methods listed above, adsorption with commercial-grade $\mathrm{AC}$, has gained the most popularity in the textile

* To whom correspondence should be addressed. E-mail: dipikaj@sitpune.edu.in industry, due to its ease of handling. However, the high cost of AC makes the technique expensive, which limits its usage as an adsorbent. ${ }^{22}$ Therefore cost-efficient, viable and durable adsorbent substances, for treatment of dye wastewater, need to be explored. In line with this, researchers have identified various efficient, low-cost and natural alternatives for AC as adsorbent. This includes grass waste, weed dust, bamboo dust, pine sawdust, coir pith, fruit shells, fruit peels, wheat straw, rice husk, sugarcane residues, eggshells and paper mill sludge. ${ }^{23-28}$

Chemical surface activation of weed biomass and its application for dye removal from wastewater is a non-traditional and revolutionary concept, which has not been explored till date. In this investigation the phenomenon of surface activation was used to treat a water hyacinth $(\mathrm{WH})$ weed biosorbent. The $\mathrm{WH}$, Eichhornia crassipes, is a free-floating, widespread and abundant noxious water weed. This weed causes water flow blockages, masks sunlight and reduces dissolved oxygen level in the water, due to its high growth rate. Quaternary ammonium salt (N-Cetyl-N, N, N-trimethyl ammonium bromide) has been used as an activating agent for surface modification in the present research. The raw and surface treated WH adsorbent has been further assessed for dye decolorization and compared with commercial-grade AC to establish its efficacy.

The study thus provides an efficient, economical and biodegradable alternative of $\mathrm{WH}$ to $\mathrm{AC}$, for the purpose of dye removal from wastewater.

\section{Experimental}

\subsection{Adsorbate}

Commercial textile dye, RBR 3BS (C.I. Reactive red 239, Make-Dye Star Ltd., India) was obtained from a textile-dying 
unit, Ruby Mills Ltd. (Khalapur, Maharashtra state, India). RBR $3 \mathrm{BS}$ is an azo anionic dye with the molecular formula $\mathrm{C}_{31} \mathrm{H}_{19} \mathrm{ClN}_{7} \mathrm{O}_{19} \mathrm{~S}_{6} .5 \mathrm{Na}$ and molecular weight $1136.32 \mathrm{~g} \mathrm{~mol}^{-1}$. The dye is water-soluble, dark reddish-brown, characterized by the presence of five sulfonic acid groups and one azo group. (Fig. 1) Due to conjugated double bonds present, this dye gives a wavelength maxima $(\gamma) 540 \mathrm{~nm}$, in the visible region.

\subsection{Preparation of Adsorbent}

In this study two new adsorbents were investigated, namely untreated and treated WH adsorbents, in comparisson with AC. The preparation of the two new adsorbents is sumarized as a flow chart in Fig. 2.

\subsubsection{Preparation of Untreated Adsorbent}

Fresh green, fully grown WH plants were randomly pulled out from Pashan Lake, in Pune city, Maharashtra State, India (18.53 $\mathrm{N}, 73.78^{\circ} \mathrm{E}$ ). As shown in Fig. 2, the plants were washed under running water and then with distilled water to remove dust and dirt. The roots, stems and leaves of WH were separated, and dehydrated in natural sunlight for five days, followed by dehy- dration in an oven at $90{ }^{\circ} \mathrm{C}$ for $8 \mathrm{~h}$. Plant parts were ground and sieved separately using 'Indian standards (IS): $355^{\prime}$ sieves. These powdered untreated adsorbents of the roots, stems and leaves were kept separately in sealed containers.

\subsubsection{Surface Modification of Untreated Adsorbent}

Cellulose and hemicellulose are present, in variable percentages, in the roots, stems and leaves of WH. The order of percentage is $\mathrm{WH}$ stems $>\mathrm{WH}$ roots $>\mathrm{WH}$ leaves..$^{29}$ Every cellulose molecule, at the adsorbent surface, contained a negatively charged free $\mathrm{OH}$ group, which is the binding site for positively charged quaternary ammonium cation. ${ }^{30}$ Thus, the extent of surface modification is dependent on the percentage cellulose present in the roots, stems and leaves of the mentioned adsorbent.

$\mathrm{N}$-Cetyl-N,N,N-trimethyl ammonium bromide, a quaternary ammonium salt (A.R. grade, Thomas Baker, India) was used as an activating agent for surface treatment. Each of the untreated adsorbent powders of the roots, stems and leaves of WH were allowed to mix and were agitated with $0.5 \% \mathrm{w} / \mathrm{v}$ aqueous solution of activation agent at room temperature for $30 \mathrm{~min}$, separately (see Fig. 2). This resulted in the surface activation of<smiles>O=S(=O)(O[Na])OCCS(=O)(=O)c1cccc(Nc2nc(Cl)nc(Nc3cc(S(=O)(=O)O[Na])cc4cc(S(=O)(=O)O[Na])c(N=Nc5ccc6c(S(=O)(=O)O)cccc6c5S(=O)(=O)O)c(O)c34)n2)c1</smiles>

Figure 1 Structure of RBR 3BS dye (C.I. Reactive red 239).

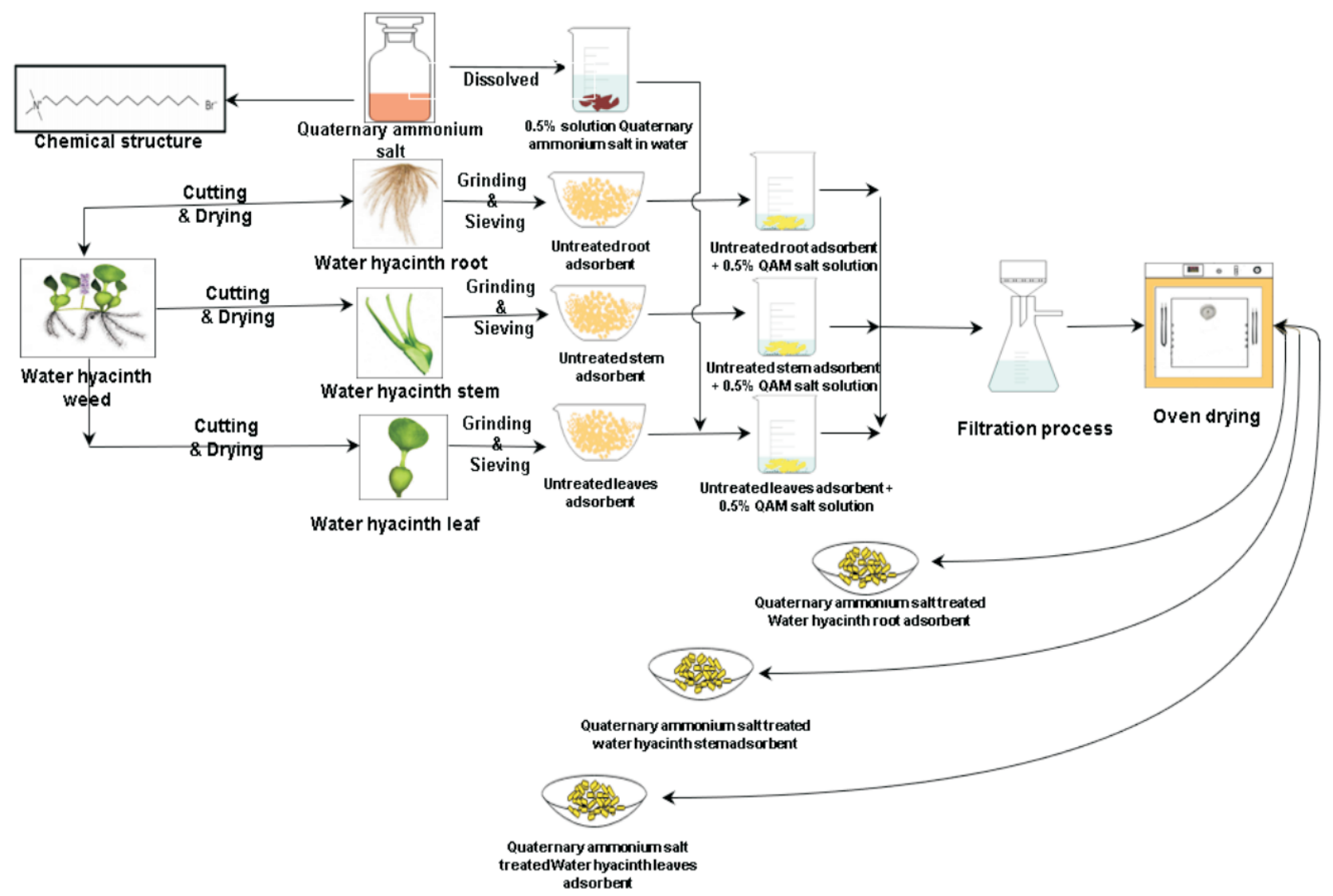

Figure 2 Flow chart for the preparation of raw and surface-modified adsorbents. 
the adsorbents of the roots, stems and leaves. The treated adsorbents were then separately filtered, dehydrated at $105{ }^{\circ} \mathrm{C}$ and kept in airtight containers.

\subsection{Characterization of Adsorbents}

The untreated and treated adsorbents were analyzed using FTIR (Fourier Transformed Infrared Spectroscopy, Bruker, Model-TENSOR 27, USA), SEM (Scanning Electron Microscopy, JEOL, Model-JSM-6360A, USA), CHNO analyzer (CarbonHydrogen-Nitrogen-Oxygen analyzer, Thermo, Model- FLASH EA1112, USA) and PZC (Point of Zero Charge) techniques, through which the surface modification was confirmed.

\subsection{Adsorption Studies}

\subsubsection{Untreated Adsorbents}

Preliminary batch studies investigated the adsorption capacity of raw adsorbent of roots, stems and leaves of $\mathrm{WH}$ for the decolorization of RBR 3BS dye. In these studies $0.2 \mathrm{~g}$ of the raw adsorbent (roots, stems or leaves of $\mathrm{WH}$ ) was shaken, using a rotary shaker, with $40 \mathrm{~mL}\left(4.5 \times 10^{-5} \mathrm{~mol} \mathrm{~L}^{-1}\right)$ aqueous dye solution in a glass conical flask at $100 \mathrm{rpm}$. The studies were conducted under normal conditions of temperature $\left(30^{\circ} \mathrm{C}\right)$ and $\mathrm{pH}$ $(\mathrm{pH} 5.8)$ of the dye solution. After sufficient contact time (180 min), filtration was carried out using Whatman 42 paper. Examination of the filtrate for the percentage dye decolorization was done spectrophotometrically, using a double-beam spectrophotometer (Make-Systronics, Model-SMART 2203, India). Based on these preliminary studies and using the equations (Equations 1 and 2) below, the dye adsorption capacity and percentage dye decolorization were calculated for the adsorbent samples.

$$
\begin{aligned}
& q_{e}=v \frac{c_{0}-c_{e}}{W} \\
& \% A=\frac{d_{0}-d_{e}}{d_{0}} \times 100
\end{aligned}
$$

where, $\mathrm{q}_{\mathrm{e}}$ is adsorption capacity in $\left(\mathrm{mg} \mathrm{g}^{-1}\right), v$ denotes the volume of solution in (L), $\mathrm{C}_{\mathrm{e}}$ and $\mathrm{C}_{0}$ signify equilibrium and initial dye concentrations, respectively, in $\left(\mathrm{mg} \mathrm{L}^{-1}\right)$, and $\mathrm{W}$ represents the adsorbent mass material in $(\mathrm{g})$. \% A represents the percentage dye decolorization, $d_{0}$ is initial absorbance and $d_{e}$ is the final absorbance.

\subsubsection{Treated Adsorbents and AC}

Batch studies were performed on the treated stems of WH and commercial grade AC. The analysis was carried out in conical glass flasks of $250 \mathrm{~mL}$ capacity, containing $100 \mathrm{~mL}$ dye solution. Various physicochemical process parameters like $\mathrm{pH}$ (2 to 11), contact time (up to $60 \mathrm{~min}$ ), adsorbent dosage (0.025 to $0.5 \mathrm{~g}$ ), temperature of experimental solution $\left(27^{\circ} \mathrm{C}\right.$ to $\left.50^{\circ} \mathrm{C}\right)$ and initial dye concentration $\left(1 \times 10^{-5}\right.$ to $\left.10 \times 10^{-5} \mathrm{~mol} \mathrm{~L}^{-1}\right)$ were assessed for their impact on dye decolorization. After attainment of equilibrium, filtration was carried out using Whatman filter paper 42 and concentration of unabsorbed adsorbate was estimated spectrophotometrically.

Adsorption study was strategically performed on each physicochemical process parameter individually, keeping the other parameters constant to find a set of conditions for maximum dye uptake. Investigations were carried out in triplicate for each physicochemical process parameter. The precision of the process was established with SD (standard deviation) and RSD (relative standard deviation) statistical functions.

\subsubsection{Adsorption Isotherms}

Adsorption isotherms provide an empirical relation, at a constant temperature, between dye adsorbed by adsorbent and concentration at equilibrium. In the current research, Freundlich and Langmuir adsorption isotherm models were thoroughly compared and examined for the adsorption data obtained.

Freundlich suggests multilayer adsorption at rough or heterogenous and irregular surfaces. ${ }^{35}$ Langmuir postulates monolayer adsorption..$^{34}$ Langmuir isotherm assumes a uniform distribution of the adsorbate over the adsorbent. Similarly, the adsorbed molecules and immobilized molecules do not interact in the solution.

Freundlich (Equation 3) and Langmuir (Equation 4) isotherms are expressed by following equations.

$$
\begin{gathered}
\log \mathrm{q}_{\mathrm{e}}=\log \mathrm{K}_{\mathrm{f}}+\frac{1}{\mathrm{n}} \log \mathrm{C}_{\mathrm{e}} \\
\frac{1}{\mathrm{q}_{\mathrm{e}}}=\frac{1}{\mathrm{Q}_{\max }}+\frac{1}{\mathrm{bQ}_{\max } \mathrm{C}_{\mathrm{e}}}
\end{gathered}
$$

where, $1 / n$ and $K_{f}$ are Freundlich constants associated with adsorption intensity and adsorption capacity, respectively. $\mathrm{q}_{\mathrm{e}}$ $\left(\mathrm{mg} \mathrm{g}^{-1}\right)$ is the adsorption capacity and $\mathrm{C}_{\mathrm{e}}\left(\mathrm{mg} \mathrm{L}^{-1}\right)$ the concentration at equilibrium, respectively. Similarly, $Q_{\max }$ represents adsorption in a monolayer $\left(\mathrm{mol} \mathrm{g}^{-1}\right)$ and Langmuir constant is represented by $\mathrm{b}\left(\mathrm{L} \mathrm{mol}^{-1}\right)$.

\subsection{Kinetic Studies}

Adsorption kinetics is mainly concerned with the mechanism and rate of chemical or physical change. The rate-determining step in the mechanism of chemical change was explored with the help of kinetic modelling. In the present investigation the Lagergren's pseudo-first-order (Equation 5), Lagergren's pseudo-second-order (Equation 6) and Elovich (Equation 7) models were studied and applied to the sorption data.

$$
\begin{aligned}
& \log \left(\mathrm{q}_{\mathrm{e}}-\mathrm{q}_{\mathrm{t}}\right)=\log \mathrm{q}_{\mathrm{e}}+\frac{\mathrm{K}_{1}}{2.303} \mathrm{t} \\
& \frac{t}{\mathrm{q}_{\mathrm{t}}}=\frac{1}{\mathrm{~K}_{2} \mathrm{q}_{\mathrm{e}}^{2}}+\frac{t}{\mathrm{q}_{\mathrm{e}}} \\
& \mathrm{q}_{\mathrm{t}}=\frac{1}{\beta} \ln (\alpha \beta)+\frac{1}{\beta} \ln (\mathrm{t})
\end{aligned}
$$

In the above expressions, $\mathrm{K}_{1}\left(\mathrm{~L} \mathrm{~min}^{-1}\right)$ denotes the equilibrium rate constant of Lagergren's pseudo-first-order adsorption, $\mathrm{K}_{2}$ $\left(\mathrm{g} \mathrm{mg}^{-1} \mathrm{~min}^{-1}\right.$ ) represents the rate constant of Lagergren's pseudo-second-order adsorption, $\mathrm{q}_{\mathrm{e}}\left(\mathrm{mg} \mathrm{g}^{-1}\right)$ and $\mathrm{q}_{\mathrm{t}}\left(\mathrm{mg} \mathrm{g}^{-1}\right)$ refer to the dye adsorbed at equilibrium and at any time $(\mathrm{t}, \mathrm{min})$, respectively. $\alpha\left(\mathrm{mg} \mathrm{g}^{-1} \mathrm{~min}^{-1}\right)$ is the rate constant of chemisorption, and $\beta$ is constant related to the surface coverage.

Adsorption of RBR 3BS on treated $\mathrm{WH}$ and $\mathrm{AC}$ was proposed to take place via either film diffusion or particle diffusion. Movement of adsorbate molecules towards the external surface of adsorbent (external transport $>$ internal transport) takes place in film diffusion, whereas transport of adsorbate within the pores of the adsorbent (external transport < internal transport) is seen in particle diffusion. ${ }^{31}$

To distinguish between these two diffusion mechanisms, and to determine the exact rate-controlling step, Boyd's diffusion model was applied to the experimental data. Boyd's model postulates the dominance of film diffusion or particle diffusion with the help of standard equations (Equations 8-12). ${ }^{31}$

$$
\mathrm{F}=\frac{\mathrm{Q}_{\mathrm{t}}}{\mathrm{Q}_{\infty}}
$$




$$
\begin{aligned}
& \mathrm{B}_{\mathrm{t}}=-0.4977-\ln (1-\mathrm{F}) \\
& \mathrm{D}_{\mathrm{i}}=\mathrm{D}_{0} \exp \left(\frac{-\mathrm{E}_{\mathrm{a}}}{R T}\right) \\
& \mathrm{D}_{0}=\left(2.72 \mathrm{~d}^{2} \mathrm{kt}\right) \cdot \exp \left(\frac{\Delta \mathrm{S} \#}{R}\right) \\
& \mathrm{B}=\left(\pi^{2} \mathrm{D}_{\mathrm{i}} / \mathrm{r}^{2}\right)
\end{aligned}
$$

In the above equations, $\mathrm{F}$ is fractional attainment of equilibrium at a given time $\mathrm{t}$, where $\mathrm{q}_{\infty}$ and $\mathrm{q}_{\mathrm{t}}$ represent dye adsorption capacities at infinity and at time $(t, \mathrm{~min})$, respectively. $\mathrm{B}_{\mathrm{t}}$ is a function of $\mathrm{F},-0.4977$ is a constant value obtained from Reichenberg table for F-value $>0.85 . \mathrm{D}_{\mathrm{o}}\left(\mathrm{cm}^{2} \mathrm{~min}^{-1}\right)$ and $\mathrm{D}_{\mathrm{i}}\left(\mathrm{cm}^{2} \mathrm{~min}^{-1}\right)$ stand for pre-exponential factor and effective diffusion coefficient, respectively. $\mathrm{E}_{\mathrm{a}}\left(\mathrm{J} \mathrm{mol}^{-1}\right)$ represents activation energy, $\mathrm{R}\left(\mathrm{J} \mathrm{K}^{-1} \mathrm{~mol}^{-1}\right)$ signifies the universal gas constant, $\mathrm{d}(\mathrm{cm})$ is adsorbent successive site average distance, $\mathrm{k}\left(\mathrm{J} \mathrm{K}^{-1}\right)$ denotes Boltzmann constant and $\Delta S \#\left(\mathrm{~J} \mathrm{~K}^{-1} \mathrm{~mol}^{-1}\right)$ represents entropy of the system, and $\mathrm{r}$ is the radius of adsorbent particle calculated from mesh size.

From the above expressions, the values of fractional attainment $(F)$ and $B_{t}$ were calculated to plot $B_{t}$ vs. $t$ (Boyd's plot) graphs. From the slope of these plots (i.e. $B$ ) values of $D_{i}$ and $D_{o}$ were estimated, which were useful to distinguish between film and particle diffusion..$^{32}$ According to Boyd's model, if the plots of $B_{t}$ vs. t produces straight line passing through the origin, then intra particle diffusion acts as a rate-determining step. However, if the lines were not straight/curved or linear, but not passes through origin then film diffusion is dominant. ${ }^{32}$ The application of Boyd's model thus essentially distinguishes between the two-adsorption mechanisms (namely particle diffusion and film diffusion) to estimate the rate-determining step of adsorption.

\subsection{Thermodynamic Studies}

Thermodynamic studies mainly deal with the spontaneity and feasibility of chemical change. Thermodynamic studies are also helpful to estimate adsorption mechanisms in adsorption studies. ${ }^{34}$ The heat of formation of products and temperature of deformation of reactants govern the exothermic and endothermic adsorption nature. In the present investigation, thermodynamic parameters like change in entropy $(\Delta S)$, Gibbs free energy $(\Delta \mathrm{G})$, and change in enthalpy $(\Delta \mathrm{H})$ were computed using the relations below (Equations 13-15).

$$
\begin{aligned}
& \Delta \mathrm{G}=-\mathrm{RT} \ln \mathrm{b} \\
& \Delta \mathrm{H}=-\mathrm{R}\left(\frac{\mathrm{T}_{2} \mathrm{~T}_{1}}{\mathrm{~T}_{2}-\mathrm{T}_{1}}\right) \ln \left(\frac{\mathrm{b}_{2}}{\mathrm{~b}_{1}}\right) \\
& \Delta \mathrm{S}=\frac{\Delta \mathrm{H}-\Delta \mathrm{G}}{\mathrm{T}}
\end{aligned}
$$

In the expression above, $\mathrm{b}$ represents the Langmuir constant, $\mathrm{R}\left(\mathrm{J} \mathrm{K}^{-1} \mathrm{~mol}^{-1}\right)$ is universal gas constant and $\mathrm{T}(\mathrm{K})$ represents temperature.

\subsection{Error Analysis}

Statistical error analysis is a vital tool to compare experimental variance with theoretical variance to establish accuracy of any model. ${ }^{36}$ To ascertain the error distribution associated with the system error functions, viz. $\chi^{2}$ (chi-square) (Equation 16), $\Sigma$ ABS (sum of absolute errors) (Equation 17) and NSD (normalized standard deviation) (Equation 18) were studied. These error functions were applied to kinetic and isothermal models to validate the experimental values.

$$
\begin{aligned}
& \chi^{2}=\frac{\sum_{\mathrm{i}=1}^{\mathrm{N}}\left(\mathrm{q}_{\text {e exp }}-\mathrm{q}_{\text {e model }}\right)}{\mathrm{q}_{\text {e exp }}} \\
& \sum \mathrm{ABS}=\sum_{\mathrm{i}=1}^{\mathrm{N}}\left|\mathrm{q}_{\text {e exp }}-\mathrm{q}_{\text {e model }}\right| \\
& \mathrm{NSD}=100 \sqrt{\frac{\sum\left[\left(\mathrm{q}_{\text {e exp }}-\mathrm{q}_{\text {e model }}\right)\right]^{2}}{\mathrm{~N}}}
\end{aligned}
$$

where $\mathrm{q}_{\mathrm{e}}\left(\mathrm{mg} \mathrm{g}^{-1}\right)$ is the modelled dye adsorption capacity, $\mathrm{q}_{\mathrm{e} \text { exp. }}$. $\left(\mathrm{mg} \mathrm{g}^{-1}\right)$ is the experimental dye adsorption capacity and $\mathrm{N}$ is the number of observations.

\section{Results and Discussion}

\subsection{Characterization of Adsorbents}

\subsubsection{FTIR}

FTIR spectra of untreated WH stem adsorbent (Fig. 3a) showed some key vibrational peaks in the fingerprint region. The peak observed at $1029 \mathrm{~cm}^{-1}$ was due to $\mathrm{C}-\mathrm{O}$ stretching. Signals at $1319 \mathrm{~cm}^{-1}, 1369 \mathrm{~cm}^{-1}$ and $1423 \mathrm{~cm}^{-1}$ indicated $\mathrm{C}-\mathrm{H}$ bending. Peaks observed at $1623 \mathrm{~cm}^{-1}$ and $1737 \mathrm{~cm}^{-1}$ were owing to $\mathrm{C}=\mathrm{C}$ and $\mathrm{C}=\mathrm{O}$ stretching vibrations, respectively. Similarly, functional group region consisted of peaks at $2918 \mathrm{~cm}^{-1}$ and $3333 \mathrm{~cm}^{-1}$ for $\mathrm{C}-\mathrm{H}$ and $\mathrm{O}-\mathrm{H}$ stretching vibrations, respectively. The last-mentioned peaks in spectra were due to carbohydrate and cellulose moieties present in the untreated adsorbent.

After surface modification, the treated stem adsorbent (Fig 3a) showed a variation in the case of the two characteristic peaks at $2854 \mathrm{~cm}^{-1}$ and $2918 \mathrm{~cm}^{-1}$. This variation was due to the $\mathrm{C}-\mathrm{H}$ stretching due to the presence of alkyl groups associated with $\mathrm{N}$-Cetyl-N,N,N-trimethyl ammonium bromide (activation agent), confirming surface modification. Other than this, all the other peak patterns remained unchanged. The FTIR spectra of untreated and treated $\mathrm{WH}$ stem adsorbents highlighted the functional group change.

In case of AC, the FTIR spectra (Fig. 3b) contained peaks at $443 \mathrm{~cm}^{-1}, 479 \mathrm{~cm}^{-1}, 511 \mathrm{~cm}^{-1}, 545 \mathrm{~cm}^{-1}$ and $576 \mathrm{~cm}^{-1}$ due to $\mathrm{C}-\mathrm{H}$ bending. Peak at $1556 \mathrm{~cm}^{-1}$ indicated $\mathrm{C}=\mathrm{C}$ stretching.
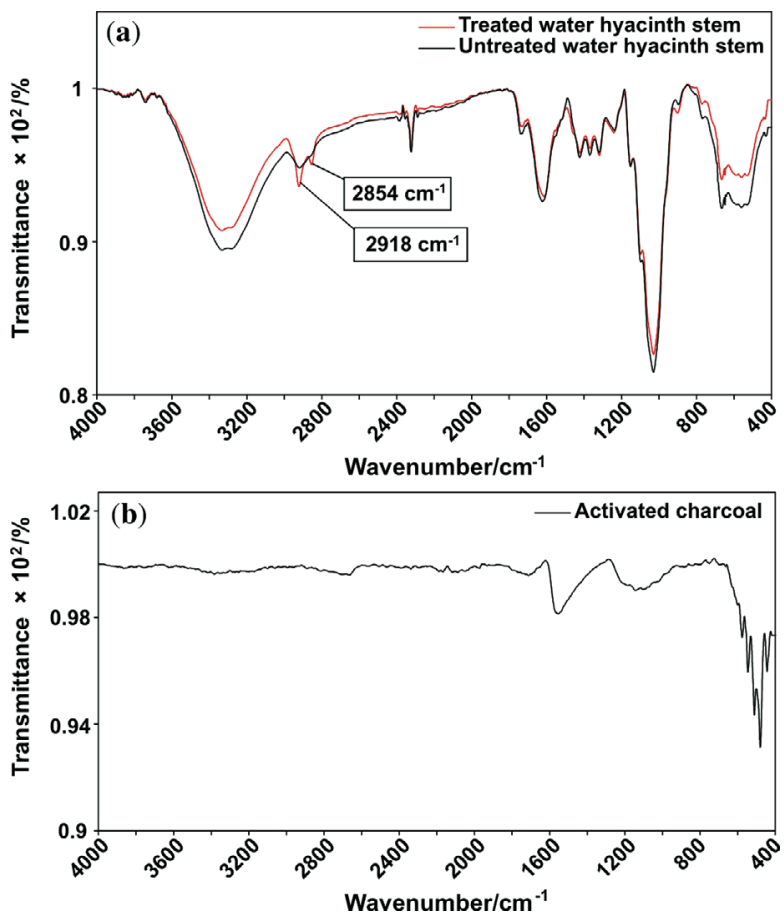

Figure 3 (a) Overlay of FTIR spectra for untreated and treated WH stem adsorbents and (b) FTIR spectrum of activated charcoal adsorbent. 


\subsubsection{SEM}

SEM images show untreated WH stem adsorbent (Fig. 4a), treated WH stem adsorbent (Fig. 4b) and AC adsorbent (Fig. 4c). Based on visual observation, the untreated WH stem adsorbent showed a lumpy and less porous morphology, whereas treated WH stem adsorbent revealed a soft and highly porous morphology. Activation of the adsorbent thus increased the porosity, and this increased the adsorption capacity. SEM image of AC showed a rough and an uneven surface with a porous texture. The SEM images were useful in morphological elucidation.

\subsection{3. $\mathrm{CHNO}$}

$\mathrm{CHNO}$ analysis was performed to understand the changes in the chemical composition of untreated and treated $\mathrm{WH}$ adsorbents. The elemental content of untreated WH adsorbent, for nitrogen $(\mathrm{N})$, carbon $(\mathrm{C})$, oxygen $(\mathrm{O})$ and hydrogen $(\mathrm{H})$ was $0.12 \%, 32.60 \%, 62.33 \%$ and $4.95 \%$, respectively, whereas, the same for treated WH adsorbent was $6.41 \%, 40.50 \%, 51.72 \%$ and $1.37 \%$, respectively. The increase in the percentage of carbon, hydrogen and nitrogen in the treated $\mathrm{WH}$ was due to an increased carbon, hydrogen, and nitrogen load of the activation agent $\mathrm{N}$-Cetyl-N,N,N-trimethyl ammonium bromide. This compositional change confirmed that activation took place. Elemental content of $\mathrm{AC}$, which gave the percentage of nitrogen $(\mathrm{N})$, carbon $(\mathrm{C})$, oxygen $(\mathrm{O})$ and hydrogen $(\mathrm{H})$ as $3.75 \%, 71.00 \%$, $22.75 \%$ and $2.50 \%$, respectively, was also determined for comparison.

\subsubsection{PZC}

The activation process was also confirmed by PZC determination, using the ' $\mathrm{pH}$ drift' method. The graphs of final $\mathrm{pH}$ vs. initial $\mathrm{pH}$ values were plotted for untreated and treated $\mathrm{WH}$ stems adsorbents (Fig. 5a and Fig. 5b). The PZC analysis indicated the residual surface charge on untreated and treated $\mathrm{WH}$ stems adsorbents. The PZC for untreated WH stems adsorbent was found to be 6.2 , suggesting anionic charges at the surface, whereas for treated WH stems adsorbent the value of PZC was

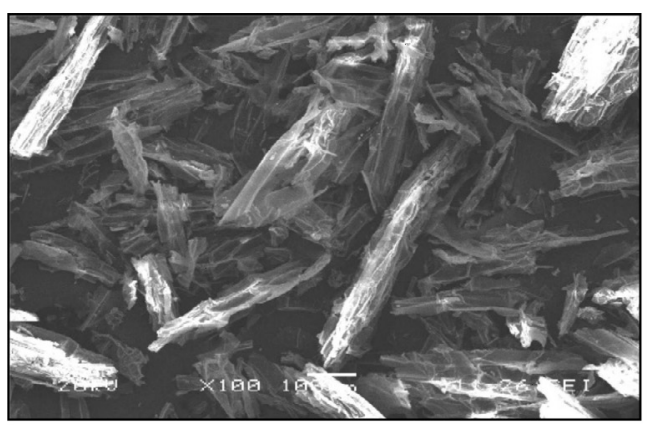

(a) found to be 8.0, inferring a cationic charge at surface. The phenomenon thus supported the activation process, where the negatively charged untreated adsorbent became positively charged after surface modification.

\subsection{Adsorption Studies}

In preliminary analysis, WH roots, stems and leaves adsorbents in the untreated form showed $22.7 \%\left(23.7 \mathrm{mg} \mathrm{g}^{-1}\right), 29.5 \%$ $\left(30.8 \mathrm{mg} \mathrm{g}^{-1}\right)$ and $18.1 \%$ (18.9 $\left.\mathrm{mg} \mathrm{g}^{-1}\right)$ dye decolorization and adsorption capacities, respectively. After surface modification the treated adsorbents were again analyzed and showed $89.8 \%$ and $93.8 \mathrm{mg} \mathrm{g}^{-1}, 99.8 \%$ and $104.2 \mathrm{mg} \mathrm{g}^{-1}$, and $89.1 \%$ and $93.0 \mathrm{mg} \mathrm{g}^{-1}$ dye removal for root, stem and leaves, respectively Thus, surface modification treatment increased the dye decolorization capacity of untreated WH adsorbents. The order of dye decolorization capacity was in line with the percentage cellulose content in the roots, stems and leaves of $\mathrm{WH}$, i.e. WH stems $>\mathrm{WH}$ roots $>\mathrm{WH}$ leaves. Out of the treated roots, stems and leaves, stems showed the highest dye decolorization activity and was selected for further investigation. Comparing with $\mathrm{WH}$ treated stem adsorbent, the AC (Commercial grade, powder form, Merck, India) showed $9.8 \%$ (10.4 $\left.\mathrm{mg} \mathrm{g}^{-1}\right)$ dye removal. Surface treated WH stem adsorbent thus exhibited highest efficiency for dye removal and provides a suitable substitute for AC.

\subsection{Impact of Physicochemical Process Parameters}

\subsubsection{Effect of $p H$}

The effect of $\mathrm{pH}$ on dye uptake by treated WH stem adsorbent and $\mathrm{AC}$ was investigated within a $\mathrm{pH}$ range of 2 to 11 . As shown in Fig. 6, low dye adsorption was observed at $\mathrm{pH} 2$ for the treated WH stems adsorbent. Low dye adsorption was due to ionic repulsion due to high positive charge accumulation at the adsorbent surface. The maximum dye adsorption for $\mathrm{WH}$ stems adsorbent was obtained at $\mathrm{pH} 3$, after which the quantity of dye adsorbed remained almost constant till $\mathrm{pH} 11$. This phenome-

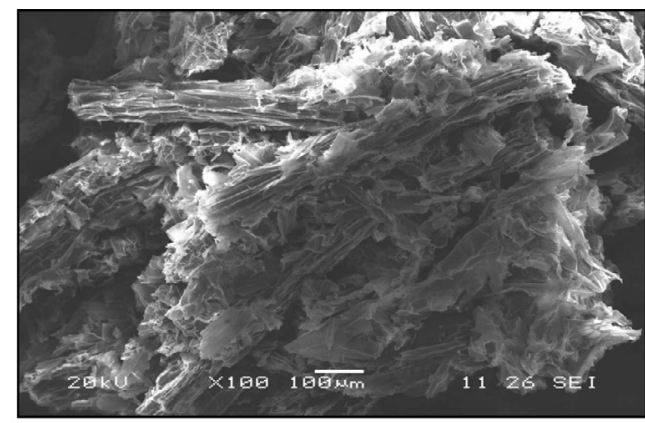

(b)

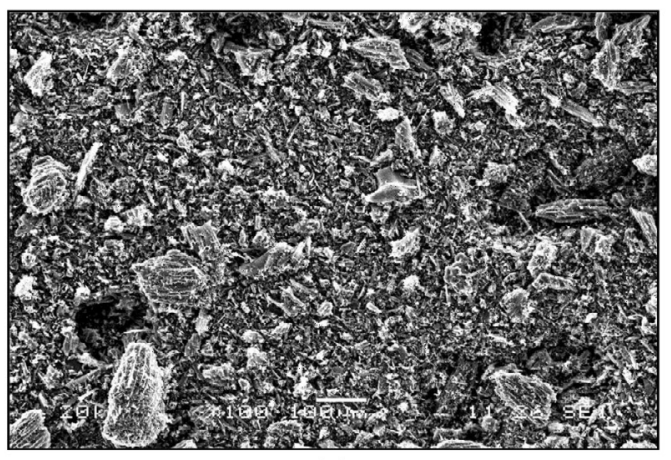

(c)

Figure 4 SEM images for (a) untreated WH stem adsorbent, (b) treated WH stem adsorbent and (c) AC adsorbent. 

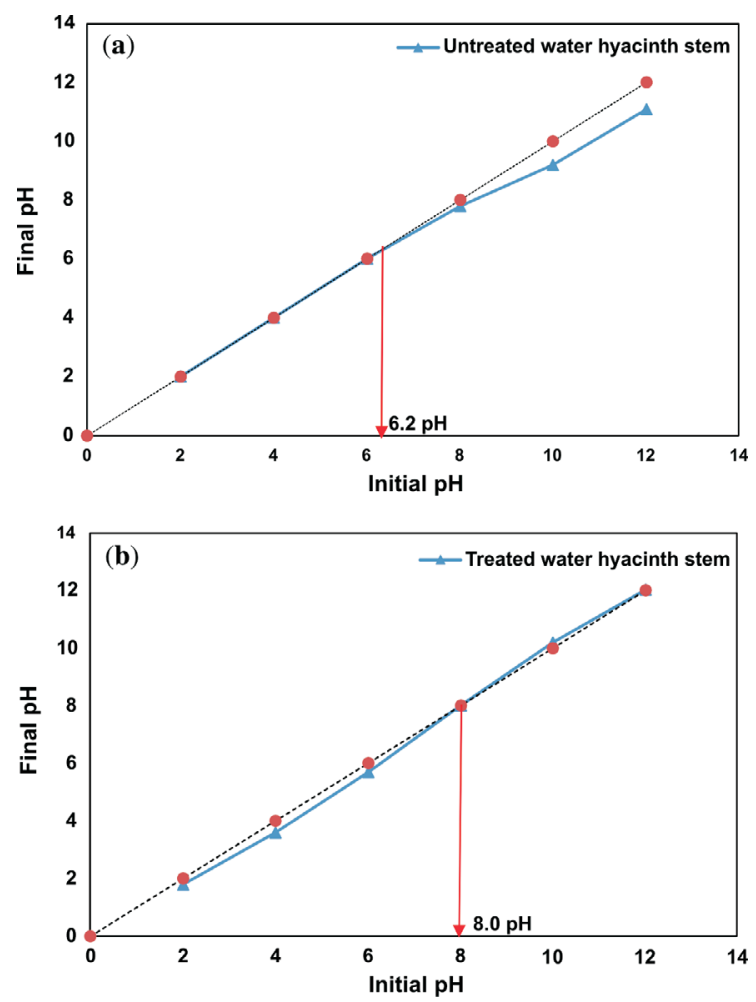

Figure 5 PZC plots for (a) untreated WH stem adsorbent and (b) treated WH stem adsorbent.

non of constant adsorption concerning $\mathrm{pH}$, was due to the role of activating agent (N-Cetyl-N,N,N-trimethyl ammonium bromide). The activating agent formed a positively charged layer over negatively charged $\mathrm{OH}$ group of the cellulose present in untreated WH stems adsorbent. Surface treatment cancelled the negative zeta potential on untreated WH stems adsorbent making it positively charged, which attracted negatively charged dye molecules in the solution. ${ }^{37}$

AC, showed a linear decrement in dye uptake from $\mathrm{pH} 2$ to 7 , and after $\mathrm{pH} 7$ adsorption remained constant till $\mathrm{pH} 11$. At low $\mathrm{pH}$, the surface of AC gets protonated due to a high positive charge, which acted as a binding site for negatively charged dye molecules resulting in high adsorption. Similar observations have been reported in the literature. ${ }^{38}$ De-protonation increased from $\mathrm{pH} 2$ to 7 , leading to electrostatic repulsion and thus
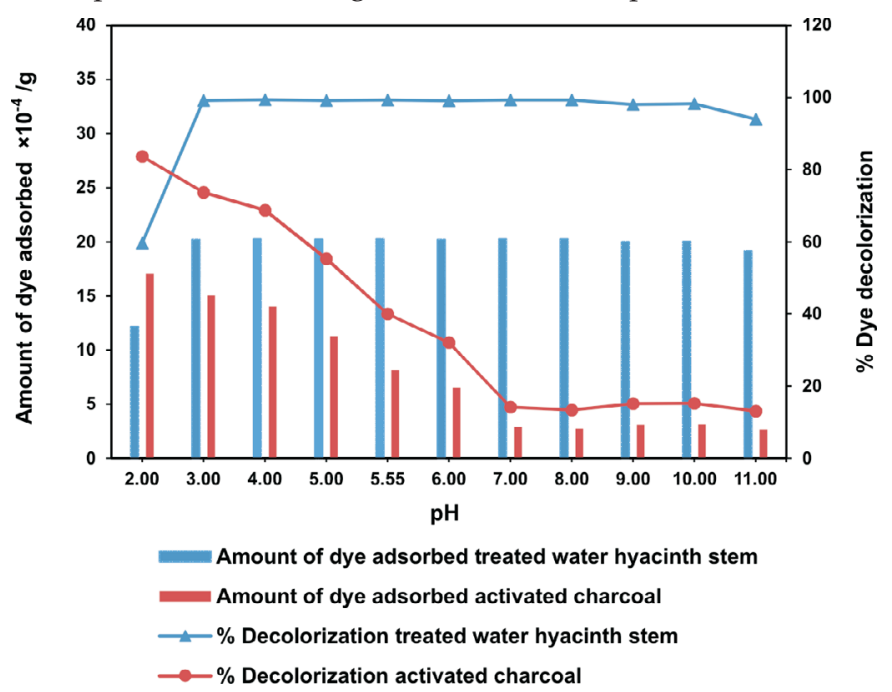

Figure 6 Effect of $\mathrm{pH}$ alteration on dye uptake for treated WH stems and $\mathrm{AC}$ adsorbents. (Dye concentration $=4.5 \times 10^{-5}\left(\mathrm{~mol} \mathrm{~L}^{-1}\right)$; adsorbent $=$ $0.2 \mathrm{~g}$; and contact time $=180 \mathrm{~min}$.). gradual diminished dye adsorption. From pH 7 onwards, adsorption remained almost constant, not reducing to zero. This phenomenon was due to the subsequent interaction like $\pi-\pi$ dispersion. ${ }^{30}$ On comparing the amount of dye adsorbed by both adsorbents; $\mathrm{pH} 3$ was selected as the optimum $\mathrm{pH}$ to carry out further batch studies.

\subsubsection{Effect of Adsorbent Dosage}

It was evident from Fig. 7 that in case of treated WH stems adsorbent, there was a gradual increase in dye adsorption from 0.025 to $0.05 \mathrm{~g}$, after adsorption stayed constant till $0.5 \mathrm{~g}$. On the other hand, AC showed a proportionate dye adsorption till $0.3 \mathrm{~g}$, beyond which it was marginal till $0.5 \mathrm{~g}$. The marginal increase or constant value of adsorption indicated active site saturation of the adsorbent surface, at a particular concentration at room temperature. As depicted in the Fig. 7, $0.05 \mathrm{~g}$ of treated WH stems adsorbent showed $52.9 \times 10^{-4} \mathrm{~g}$ dye adsorption. This was equivalent to activity showed by $0.5 \mathrm{~g}$ of AC, i.e. $51.9 \times 10^{-4} \mathrm{~g}$. Therefore, treated $\mathrm{WH}$ stems adsorbent was ten times more potent than AC for dye adsorption and had the potential to become an efficient alternative to AC.

\subsubsection{Effect of Temperature}

Temperature has a significant impact on dye adsorption. In this study, variation in dye uptake was investigated at $27^{\circ} \mathrm{C}$, $40^{\circ} \mathrm{C}$, and $50^{\circ} \mathrm{C}$ for treated WH stems and AC adsorbents (Fig. 8). In the case of treated $\mathrm{WH}$ stems adsorbent, dye adsorption slightly decreased with a rise in temperature. At $27^{\circ} \mathrm{C}$ it was $52.1 \times 10^{-4} \mathrm{~g}$, which reduced to $51.3 \times 10^{-4} \mathrm{~g}$ at $50^{\circ} \mathrm{C}$. Increase in mobility and solubility of dye molecules at high temperatures lead to desorption. However, AC adsorbent showed the opposite effect. With the increase in temperature, it showed a rise in dye adsorption from $5.2 \times 10^{-4} \mathrm{~g}$ to $10.9 \times 10^{-4} \mathrm{~g}$. This behaviour is supported by the fact that high temperature causes an increase in dye molecule penetration into the adsorbent micropores, creating new active sites and thus increasing adsorption. These contradictory results were due to the different bonding behaviour and bond strength between dye molecules and the adsorbent. ${ }^{39},{ }^{40}$ Maximum uptake capacity, i.e. dye uptake per gram of adsorbent, for the treated $\mathrm{WH}$ stems and AC adsorbent was $104.2 \mathrm{mg} \mathrm{g}^{-1}$ and $10.4 \mathrm{mg} \mathrm{g}^{-1}$ respectively, at $27^{\circ} \mathrm{C}$. Taking into consideration the efficiency and practicality, $27^{\circ} \mathrm{C}$ was found ideal for further batch studies.

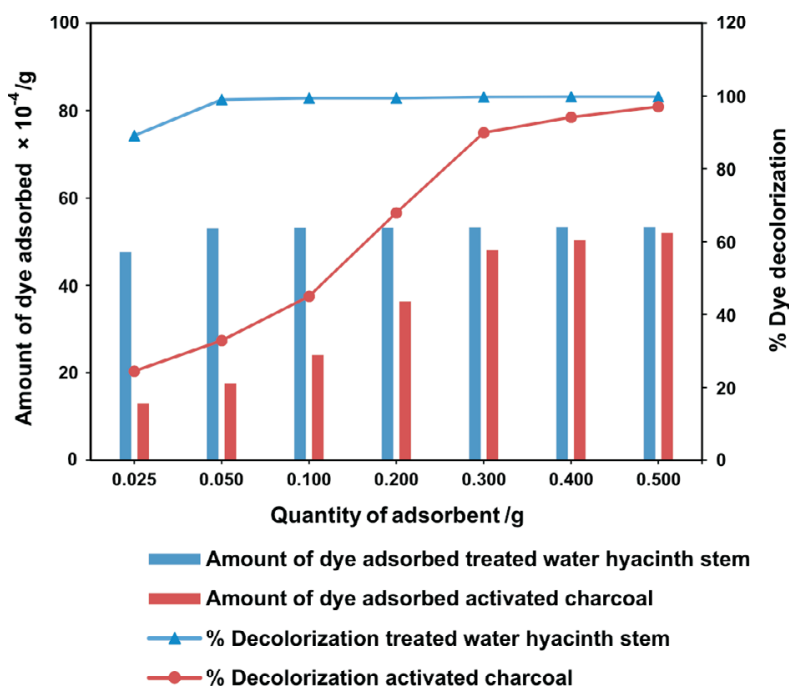

Figure 7 Effect of varying adsorbent dosage on dye uptake for treated WH stems and AC adsorbents. (Dye concentration $=4.5 \times 10^{-5}\left(\mathrm{~mol} \mathrm{~L}^{-1}\right)$; volume of dye solution $=100 \mathrm{~mL}$; and contact time $=60 \mathrm{~min}$.) 


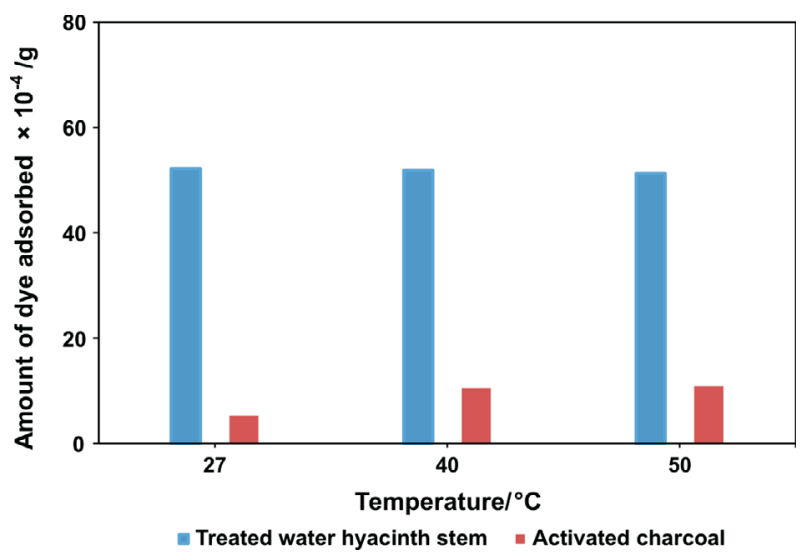

Figure 8 Effect of temperature on dye uptake for treated WH stem and activated charcoal adsorbents. (Contact time $=60 \mathrm{~min}$; dye volume $=$ $100 \mathrm{~mL} ; \mathrm{pH}=3.0$; and adsorbent dosage $=0.05 \mathrm{~g}$.)

\subsubsection{Equilibrium Concentration and Adsorption Isotherms}

Initial dye concentration is of utmost importance in adsorption studies. As seen in Fig. 9, there was a linear increase in dye uptake from $1.0 \times 10^{-5} \mathrm{~mol} \mathrm{~L}^{-1}$ to $6.0 \times 10^{-5} \mathrm{~mol} \mathrm{~L}^{-1}$, for both the adsorbents. After the mentioned concentration, the curves attained saturation or equilibrium and became non-linear. Surface diffusion was responsible for this initial linear increase in dye uptake, whereas pore diffusion was responsible for saturation. ${ }^{41}$

Taking into account the concepts of Lamberts Beers law for concentration and absorbance, ${ }^{42}$ the optimum concentration $4.5 \times 10^{-5} \mathrm{~mol} \mathrm{~L}^{-1}$ was used for batch studies. The results of batch studies were mapped with Freundlich and Langmuir isotherms (Fig. 10), to ascertain the mechanism and mode of adsorption. Error modelling was carried out on experimental results to establish the best fit model.

Freundlich plots were plotted as $\log \mathrm{q}_{\mathrm{e}} v s . \log \mathrm{C}_{\mathrm{e}}$ (Fig. 10a). The constants $n$ and $K_{f}$ were obtained from intercepts $\left(\log K_{f}\right)$ and slopes $(1 / n)$, respectively. Similarly, Langmuir isotherms were plotted as $1 / \mathrm{q}_{\mathrm{e}}$ vs. $1 / \mathrm{C}_{\mathrm{e}^{\prime}}$ (Fig. $10 \mathrm{~b}, \mathrm{c}$ ). $\mathrm{b}$ and $\mathrm{Q}_{\max }$ values were derived from intercepts $\left(1 / \mathrm{Q}_{\max }\right)$ and slopes $\left(1 / \mathrm{bQ}_{\max }\right)$, respectively. The experimental results were validated with the help chi-square, NSD, and EABS error functions (Table 1).

Table 1 shows that $\mathrm{R}^{2}$ values for the Langmuir isotherm for both the adsorbents are lower than the Freundlich isotherm;

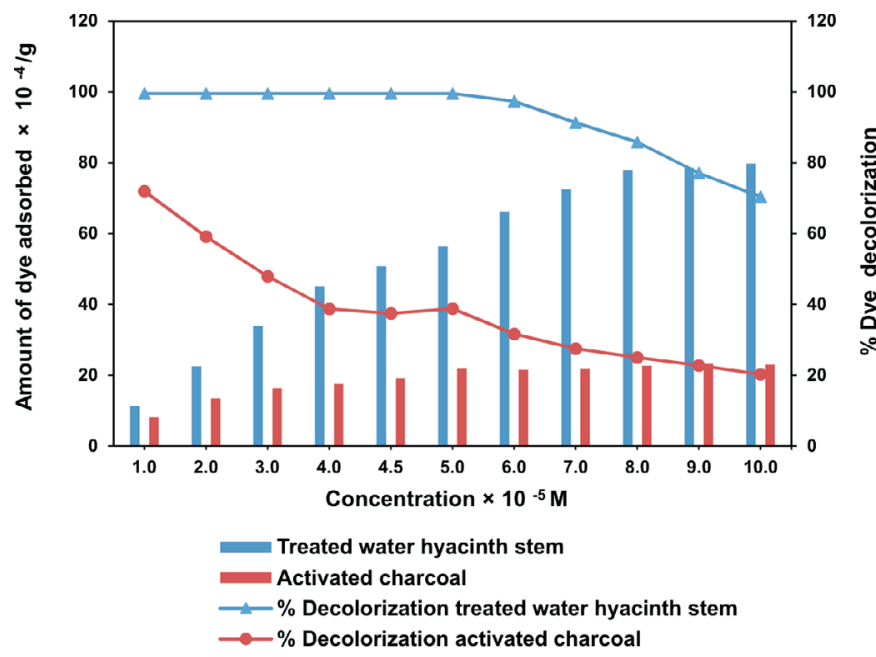

Figure 9 Effect of dye concentration on dye uptake for treated WH stems and activated charcoal adsorbents. (Contact time $=60 \mathrm{~min}$; volume of dye solution $=100 \mathrm{~mL} ; \mathrm{pH}=3.0$; and adsorbent dosage $=0.05 \mathrm{~g}$.) .
Table 1 Adsorption isotherm and error analysis parameters for treated $\mathrm{WH}$ stems and $\mathrm{AC}$ adsorbents at $27^{\circ} \mathrm{C}$.

\begin{tabular}{llcl}
\hline Isotherms & Parameters & $\begin{array}{c}\text { Treated WH stems } \\
\text { adsorbent }\end{array}$ & $\begin{array}{c}\text { AC } \\
\text { adsorbent }\end{array}$ \\
\hline Freundlich & $\mathrm{K}_{\mathrm{f}} \times 10^{-3}$ & 1.55 & 0.81 \\
& $1 / \mathrm{n}$ & 0.21 & 0.31 \\
& $\mathrm{R}^{2}$ & 0.6580 & 0.9442 \\
& $\chi^{2} \times 10^{-5}$ & 18.22 & 0.53 \\
& $\Sigma \mathrm{ABS} \times 10^{-5}$ & 35.44 & 3.75 \\
& $\mathrm{NSD}$ & 43.39 & 12.02 \\
Langmuir & $\mathrm{Q}_{\max } \times 10^{-5}\left(\mathrm{~mol} \mathrm{~g}^{-1}\right)$ & 19.41 & 4.16 \\
& $\mathrm{~b} \times 10^{5}\left(\mathrm{~L} \mathrm{~mol}^{-1}\right)$ & 51.53 & 1.83 \\
& $\mathrm{R}^{2}$ & 0.9504 & 0.9811 \\
& $\chi^{2} \times 10^{-5}$ & 3.14 & 0.09 \\
& $\Sigma \mathrm{ABS} \times 10^{-5}$ & 10.40 & 1.23 \\
& $\mathrm{NSD}$ & 18.36 & 5.36 \\
\hline
\end{tabular}

suggesting a better fit and a highest linearity for Langmuir isotherm. As per Table 1, in case of Langmuir isotherm, the values of chi-square $\left(\chi^{2}\right)$ at $27^{\circ} \mathrm{C}$ were $3.14 \times 10^{-5}$ and $0.09 \times 10^{-5}$, the values of EABS were $10.40 \times 10^{-5}$ and $1.23 \times 10^{-5}$ and the values of NSD were 18.36 and 5.36, for the treated WH stems and AC adsorbents, respectively. A smaller value of these error functions in Langmuir on comparing with Freundlich, suggested the highest accuracy and smallest deviation for the Langmuir isotherm. Thus, experimental results followed the Langmuir isotherm for adsorption, implying monolayer adsorption.
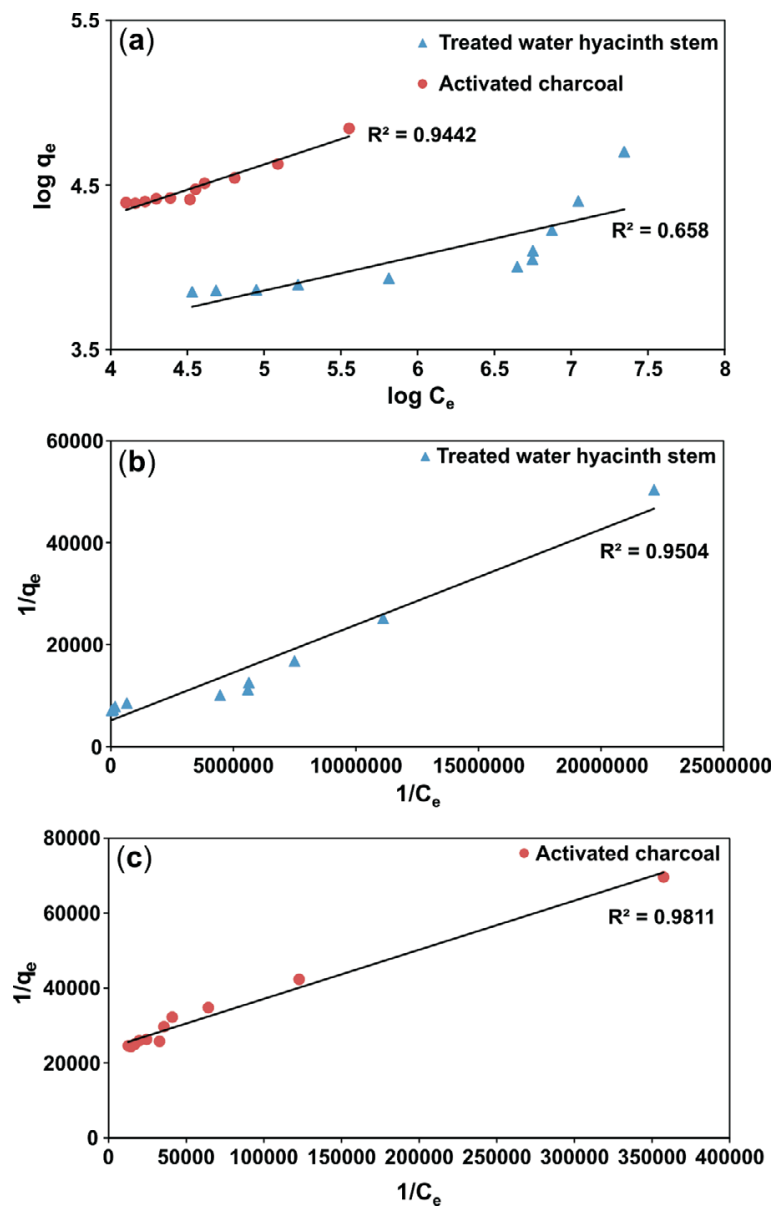

Figure 10 (a) Freundlich isotherm plot for treated WH stems and AC adsorbent. (b) Langmuir isotherm plot for treated WH stem adsorbent. (c) Langmuir isotherm plot for AC adsorbent. 


\subsubsection{Contact Time and Kinetic Studies}

Investigations to study the impact of contact time were performed with $0.05 \mathrm{~g}$ of treated $\mathrm{WH}$ stems and $\mathrm{AC}$ adsorbent at $27^{\circ} \mathrm{C}$ for $60 \mathrm{~min}$. A dye solution of $\mathrm{pH} 3.0$ and concentration $4.5 \times$ $10^{-5} \mathrm{~mol} \mathrm{~L}^{-1}$ was utilized for the experiments. After a fixed time interval of $10 \mathrm{~min}$, the aliquots were sampled and tested spectrophotometrically for dye adsorption. It is evident from Fig. 11 that, about $60-70 \%$ adsorption took place within the first $10 \mathrm{~min}$, for both adsorbents. Adsorption slowly increased till $50 \mathrm{~min}$ and attained equilibrium at $60 \mathrm{~min}$ due to active site saturation, which hindered further adsorption.

WH stem and AC adsorbent dye uptake was found to be $49.5 \times$ $10^{-4} \mathrm{~g}$ and $8 \times 10^{-4} \mathrm{~g}$, at equilibrium, respectively (Fig. 11). Thus, treated WH stems adsorbent was found to be more effective than AC adsorbent for dye removal within a reasonable contact time of $60 \mathrm{~min}$.

Kinetic evaluation was done by correlating the above data gathered from the contact time experiment with pseudo-firstorder, pseudo-second-order, and Elovich models (Fig. 12), based on regression coefficient $\left(\mathrm{R}^{2}\right)$, to ascertain the rate-controlling step of adsorption. Pseudo-first-order parameters $\mathrm{K}_{1}, \mathrm{q}_{\mathrm{e}}$ and $\mathrm{q}_{\mathrm{t}}$ were estimated from Fig. 12a, where the slope was $\left(-K_{1} / 2.303\right)$ and intercept was $\left(\log \mathrm{q}_{\mathrm{e}}\right)$. Similarly, pseudo-second-order parameters $\mathrm{K}_{2}, \mathrm{q}_{\mathrm{e}}$, and $\mathrm{q}_{\mathrm{t}}$ were obtained from Fig. 12b, where the slope was $\left(1 / \mathrm{q}_{\mathrm{e}}\right)$ and intercept was $\left(1 / \mathrm{K}_{2} \mathrm{q}_{\mathrm{e}}{ }^{2}\right)$. The Elovich constants $\alpha$ and $\beta$ were computed from Fig. 12c, where the slope was $(1 / \beta)$, and intercept was $(1 / \beta \cdot \ln \alpha . \beta)$. All these parameters are listed in Table 2.

To establish the best fit, these models were tested statistically with chi-square $\left(\chi^{2}\right)$, NSD, and $\Sigma$ ABS error functions (Table 2).

Table 2 and Fig. 12a,b,c depict that the $\mathrm{R}^{2}$ values for both the adsorbents for pseudo-second-order model were high and near unity in comparison to pseudo-first-order and Elovich models, suggesting the highest linearity and precision within the observed results. Similarly, for pseudo-second-order model, the error function chi-square $\left(\chi^{2}\right), \Sigma$ ABS and NSD were found to be $0.83 \times 10^{-1}, 5.63,1.23$ for treated WH stems adsorbent and $0.39 \times$ $10^{-1}, 1.32,2.21$ for AC adsorbent, respectively. Least value of pseudo-second-order error functions showed less deviation and highest accuracy in comparison with the pseudo-first and Elovich models at $27^{\circ} \mathrm{C}$. The above results imply the occurrence of pseudo-second-order route by the adsorbate-adsorbent system.

The adsorption of RBR 3BS dye on treated WH stem and AC

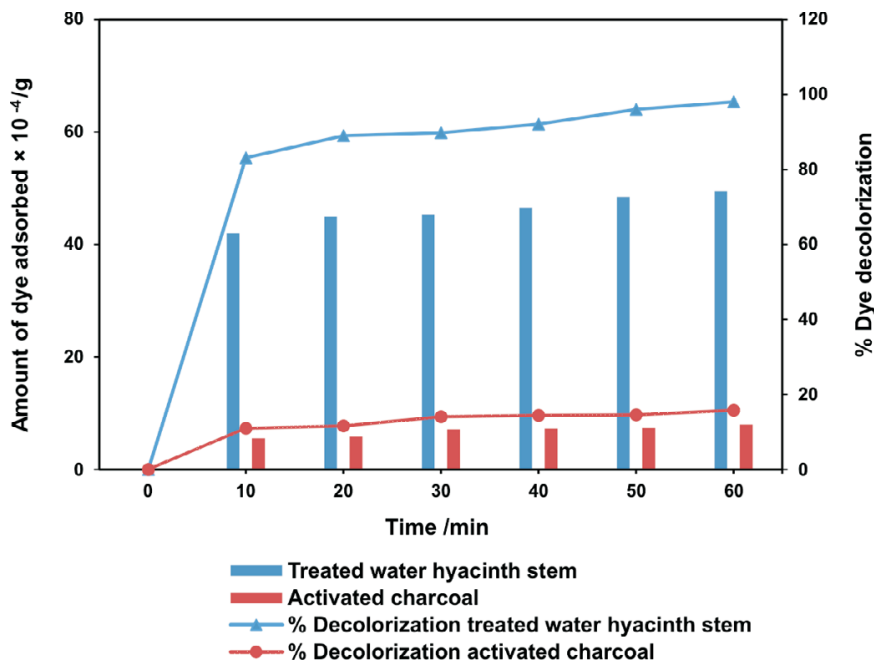

Figure 11 Effect of contact time on dye uptake for treated WH stems and $\mathrm{AC}$ adsorbents. (Dye concentration $=4.5 \times 10^{-5}\left(\mathrm{~mol} \mathrm{~L}^{-1}\right) ; \mathrm{pH}=3.0$; temperature $=27^{\circ} \mathrm{C}$; and adsorbent dosage $=0.05 \mathrm{~g}$.)
Table 2 Kinetics and error analysis parameters for treated WH stems and $\mathrm{AC}$ adsorbents at $27^{\circ} \mathrm{C}$.

\begin{tabular}{llll}
\hline Kinetic models & Parameters & $\begin{array}{c}\text { Treated WH stems } \\
\text { adsorbent }\end{array}$ & $\begin{array}{c}\text { AC } \\
\text { adsorbent }\end{array}$ \\
\hline Pseudo-first-order & $\mathrm{R}^{2}$ & 0.9164 & 0.9002 \\
& $\mathrm{~K}_{1}(1 / \mathrm{min})$ & 0.051 & 0.032 \\
& $\chi^{2} \times 10^{-1}$ & 1.98 & 1.06 \\
& $\Sigma \mathrm{ABS}$ & 6.30 & 2.14 \\
& $\mathrm{NSD}$ & 1.90 & 3.64 \\
Pseudo-second-order & $\mathrm{R}^{2}$ & $\mathbf{0 . 9 9 8 0}$ & $\mathbf{0 . 9 9 1 3}$ \\
& $\mathrm{K}_{2}\left(\mathrm{mg} \mathrm{g}^{-1} \mathrm{~min}^{-1}\right)$ & 0.003 & 0.008 \\
& $\chi^{2} \times 10^{-1}$ & $\mathbf{0 . 8 3}$ & $\mathbf{0 . 3 9}$ \\
& $\Sigma \mathrm{ABS}$ & 5.63 & $\mathbf{1 . 3 2}$ \\
& $\mathrm{NSD}^{2}$ & $\mathbf{1 . 2 3}$ & 2.21 \\
& $\mathrm{R}^{2}$ & 0.9463 & 0.9165 \\
& $\alpha\left(\mathrm{mg} \mathrm{g}^{-1} \mathrm{~min}^{-1}\right)$ & $1.78 \times 10^{-29}$ & $8.44 \times 10^{-3}$ \\
& $\beta\left(\mathrm{g} \mathrm{mg}^{-1}\right)$ & 8.40 & 2.96 \\
& $\chi^{2} \times 10^{-1}$ & 1.84 & 1.45 \\
& $\Sigma \mathrm{ABS}$ & 6.29 & 2.18 \\
& $\mathrm{NSD}$ & 1.83 & 4.43 \\
\hline
\end{tabular}

adsorbents took place via either particle diffusion or film diffusion. To determine the exact mode of adsorption and ratecontrolling step, Boyd's model was introduced. ${ }^{43}$ The values of $\mathrm{F}$ and $\mathrm{B}_{\mathrm{t}}$, were estimated from Equation 9 (ref. section 2.5) at two
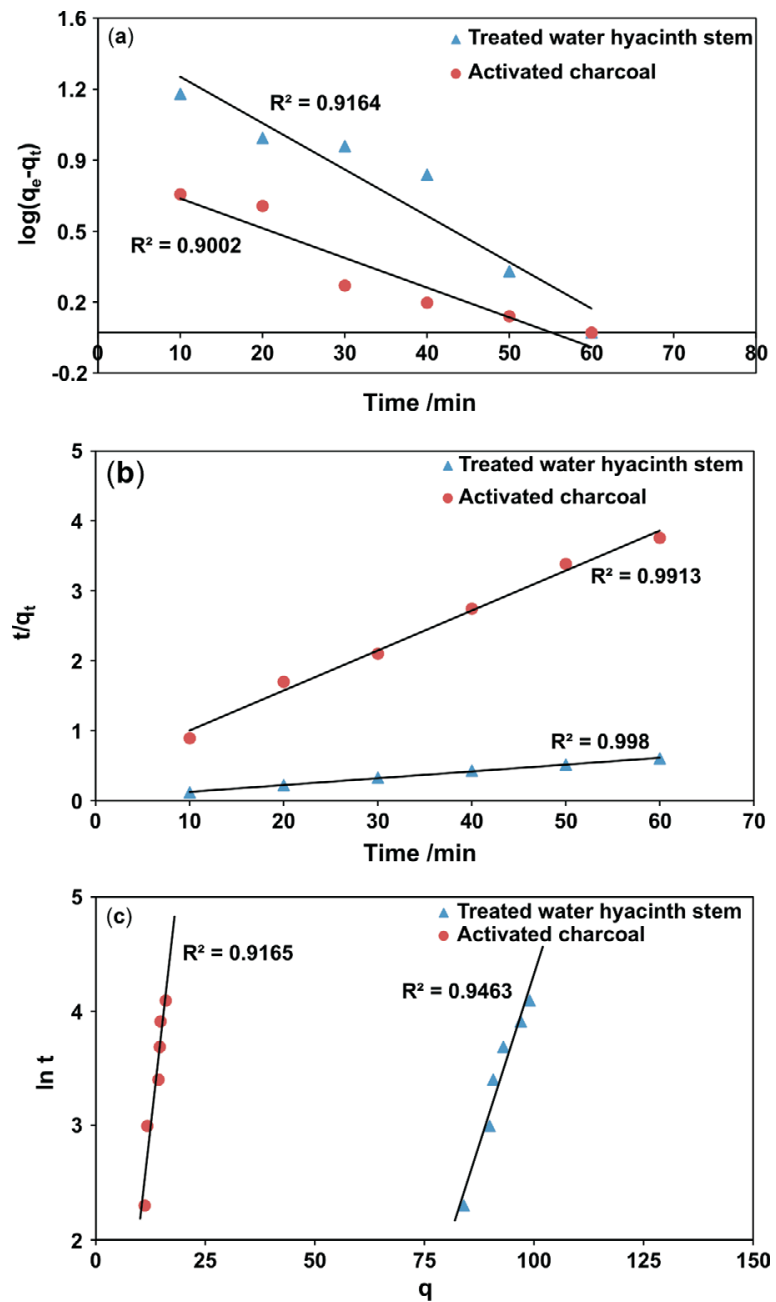

Figure 12 Plots of (a) the pseudo-first-order, (b) the pseudo-secondorder and (c) the Elovich models for treated WH stems and AC adsorbents. (Dye concentration $=4.5 \times 10^{-5}\left(\mathrm{~mol} \mathrm{~L}^{-1}\right) ; \mathrm{pH}=3.0$; adsorbent dosage $=0.05 \mathrm{~g}$; and contact time up to $60 \mathrm{~min}$.) 
distinct temperatures $27^{\circ} \mathrm{C}$ and $40{ }^{\circ} \mathrm{C}$. Further according to the Boyd's model, plots of $B_{t}$ vs. $t$ (Fig. 13) were plotted for experimental observations at $27^{\circ} \mathrm{C}$ and $40{ }^{\circ} \mathrm{C}$, and the patterns obtained were studied.

From Fig. 13 (a) and 13(b), it was observed that the plots of $B_{t} v s$. $\mathrm{t}$ for both adsorbents, viz. WH and AC at both temperatures were found to be linear (in straight line) did not pass through the origin. This observation supports the postulates of Boyd's model concluding that film diffusion was the rate-determining step. ${ }^{44,45}$ Further from the Boyd's plot, effective diffusion coefficient $\left(\mathrm{D}_{\mathrm{i}}\right)$ and pre-exponential factor $\left(D_{o}\right)$ were calculated using the slope of straight lines, i.e. B. With a shift from $27^{\circ} \mathrm{C}$ to $40^{\circ} \mathrm{C}$, there was a rise in the $D_{i}$ values $\left(1.44 \times 10^{-6}\right.$ to $\left.1.47 \times 10^{-6}\right)$ for $\mathrm{WH}$ stems adsorbent. Similarly, an increase in $\mathrm{D}_{\mathrm{i}}$ values $\left(9.63 \times 10^{-8}\right.$ to $\left.10.14 \times 10^{-8}\right)$ was also observed for AC adsorbent. This increase in $D_{i}$ value with temperature due to increased ion mobility, indicating reduction in hindering forces at a higher temperature. Fractional attainment, i.e. F, was calculated from Reichenberg's table. ${ }^{46}$ The energy of activation was computed as $8.65 \mathrm{~kJ} \mathrm{~mol}^{-1}$ and $8.98 \mathrm{~kJ} \mathrm{~mol}^{-1}$ for treated WH stems and AC adsorbent, respectively. Straight-line plots for $\log (1-\mathrm{F})$ vs. $\mathrm{t}$ for both adsorbents (not incorporated here) confirmed dye molecule external transport over the adsorbent surface, via film diffusion. Thus, film diffusion determined the rate of adsorption over both adsorbents in this study.

\subsection{System Thermodynamics}

System thermodynamics is an integral part of adsorption studies. Crucial thermodynamic parameters like change in entropy $(\Delta S)$, enthalpy $(\Delta \mathrm{H})$ and Gibbs free energy $(\Delta \mathrm{G})$, were determined (Table 3 ).

Values of DG showed the process to be spontaneous, exothermic and feasible for both the adsorbents. The values of $\Delta H$, i.e. -5.77 and $1.32 \mathrm{~kJ} \mathrm{~mol}^{-1}$ for treated WH stems and AC adsorbent, confirmed physisorption. Physisorption depended upon bonding strength of the two interacting molecules. ${ }^{47}$ Exothermic nature of adsorption caused random movement of adsorbate moieties; leading to increase in molecular disorder. Positive
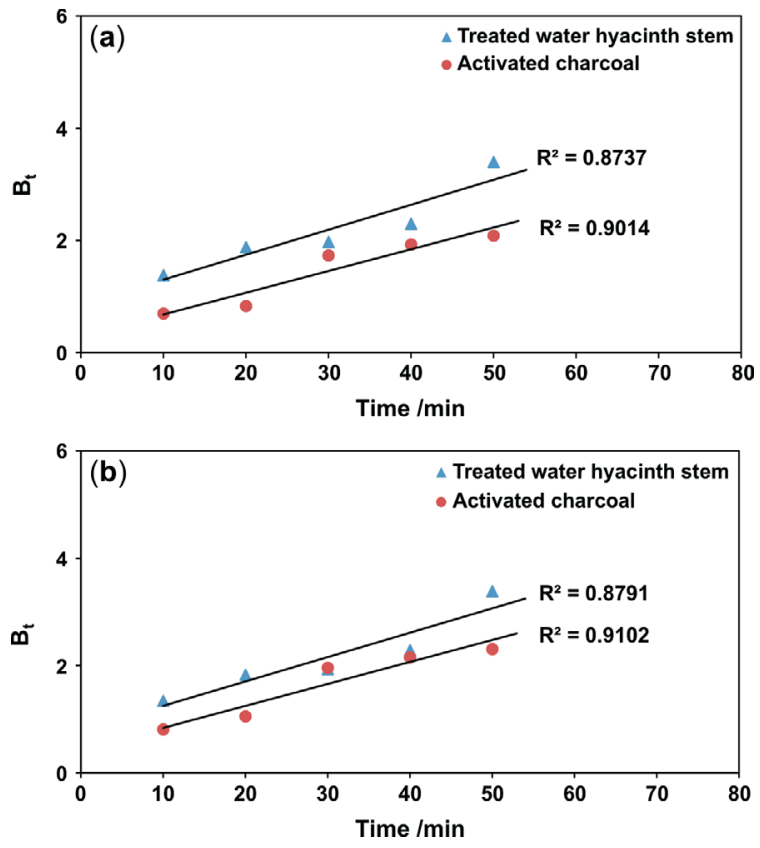

Figure 13 (a) Boyd's plot $\mathrm{B}_{\mathrm{t}}$ vs. $t$ at $27^{\circ} \mathrm{C}$ for treated $\mathrm{WH}$ stem and $\mathrm{AC}$ adsorbents (b) Boyd's plot $B_{t}$ vs. $t$ at $40{ }^{\circ} \mathrm{C}$ for treated WH stem and $A C$ adsorbents (Dye concentration $=4.5 \times 10^{-5}\left(\mathrm{~mol} \mathrm{~L}^{-1}\right) ; \mathrm{pH}=3.0$; adsorbent dosage $=0.05 \mathrm{~g}$; and contact time 0 to $60 \mathrm{~min}$.)
Table 3 Thermodynamics parameters for treated WH stems and AC.

Thermodynamic Treated WH stems adsorbent AC adsorbent
parameters

\begin{tabular}{lrr}
\hline$\Delta \mathrm{G}\left(\mathrm{kJ} \mathrm{mol}^{-1}\right)$ & -38.56 & -30.23 \\
$\Delta \mathrm{H}\left(\mathrm{kJ} \mathrm{mol}^{-1}\right)$ & -5.77 & 1.32 \\
$\Delta \mathrm{S}\left(\mathrm{J} \mathrm{K}^{-1}\right)$ & 0.10 & 0.10 \\
\hline
\end{tabular}

value of $\Delta S$ thus confirmed this randomness associated with said adsorbate-adsorbent system.

\section{Conclusion}

This study successfully demonstrated that increased adsorption is obtained via surface modification of WH adsorbent with a quaternary ammonium salt. Out of the surface-treated $\mathrm{WH}$ roots, stems and leaves adsorbents, the stems showed highest dye decolorization capacity. To further assess the efficacy, the treated WH stem adsorbent was compared with commercial-grade AC.

The optimum conditions for highest dye decolorization were $\mathrm{pH} 3$, adsorbent dosage $0.05 \mathrm{~g}$, the contact time $60 \mathrm{~min}$, initial dye concentration $4.5 \times 10^{-5} \mathrm{~mol}$. $\mathrm{L}^{-1}$ and the solution temperature $27^{\circ} \mathrm{C}$. At optimum conditions, treated WH stems adsorbent and AC showed $99.8 \%$ and $9.8 \%$ dye decolorization, respectively. Maximum adsorption capacity at $27^{\circ} \mathrm{C}$, i.e. dye uptake per gram of adsorbent, for the treated $\mathrm{WH}$ stems adsorbent and $\mathrm{AC}$ was $104.2 \mathrm{mg} \mathrm{g}^{-1}$ and $10.4 \mathrm{mg} \mathrm{g}^{-1}$, respectively. Thus, treated WH stems adsorbent was found to be 10 times more active compared to AC for dye adsorption.

The adsorption was an ideal fit for the Langmuir isotherm, proving the ongoing adsorption to be monolayer adsorption. Both adsorbent systems, i.e. treated WH stems and AC adsorbents, followed pseudo-second-order kinetics, along with film diffusion model. System thermodynamics supported the spontaneous nature of adsorption.

Chemical surface activation of $\mathrm{WH}$ thus proved its excellence for dye removal, exhibiting the effectiveness of the adsorbent and the efficiency of the process. Hence, treated WH stem adsorbent proved to be an economical, efficient, and viable alternative to commercial grade $\mathrm{AC}$ for removal of the dye.

\section{Acknowledgement}

Authors acknowledge the support provided by Ruby Mills Ltd., Khursundi, Khalapur, Dist. Raigad, India, and Symbiosis Institute of Technology, Symbiosis International (Deemed University), Lavale, Pune, India, to carry out this research activity.

\section{Supplementary Material}

Supplementary information is provided in the online supplement.

\section{${ }^{\text {sORCID iDs }}$}

S.A.Bapat: (iD) orcid.org/0000-0001-9403-7178

D.K. Jaspal: (iD) orcid.org/0000-0002-3532-8626

\section{References}

1 G.V. Kumar, P. Agrawal and L. Hiremath, Utility of plant cellulose waste for the bio adsorption of Brilliant green dye pollutant, Int. J. Chem Tech Res., 2012, 4, 319-323.

2 S. Abas, M. Ismail, M. Kamal and S. Izhar, Adsorption process of heavy metals by low cost adsorbent: a review, World Appl. Sci. J., 2013, 28, 1518-1530.

DOI: 10.5829/idosi.wasj.2013.28.11.1874 
3 D.N. Taha, I.S. Samaka, L.A. Mohammed and A.S. Naige, Adsorption studies of Direct red 28 dye onto activated carbon prepared from low cost material, Civil Environ. Res., 2014, 6, 149-159.

4 G.Z. Kyzas and M. Kostoglou, Green adsorbents for waste waters: a critical review, Materials, 2014, 7, 333-364. DOI: $10.3390 /$ ma7010333

5 M. Klavarioti, D. Mantzavinos and D. Kassinos, Removal of residual pharmaceuticals from aqueous systems by advanced oxidation processes a review, Environ. Int., 2009, 35, 402-417. DOI: 10.1016/j.envint.2008.07.009

6 H.N.H Topsakal, M. Digrak and M. Kertmen, Removal of Remazol navy blue textile dye by using Agaricus bisporus biomass, ICOEST, 2013, Nevsehir, Turkey, June 18-21.

7 A. Mittal, D. Kaur, A. Malviya, J. Mittal and V.K. Gupta, Adsorption studies on the removal of coloring agent Phenol red from waste water using waste materials as adsorbents, J. Colloid Interface Sci., $2009,337,345-354$. DOI: 10.1016/j.jcis.2009.05.016

8 I. Bazin, A. Hassine, Y. Hamouda, W. Mnif, A. Bartegi, M. Ferber, M. Waard and C. Gonzalez, Estrogenic and anti-estrogenic activity of 23 commercial textile dyes, Ecotoxicol. Environ. Saf., 2012, 85, 131-1I36. DOI: 10.1016/j.ecoenv.2012.08.003

9 W. Jungtanasombut, P. Preeprem, S. Kovitvadhi, U. Kovitvadhi and S Hannongbua, Effect of Reactive Red 239 on developing zebrafish (daniorerio) embryos, Kasetsart J. (Nat. Sci.), 2014, 48, 619-628.

10 K. Shakir, A.F. Elkafrawy, H.F. Ghoneimy, S.G.E. Beheir and M. Refaat, Removal of Rhodamine B (a basic dye) and Thoron (an acidic dye) from dilute aqueous solutions and waste water stimulants by ion flotation, Water Res., 2010, 44, 1449-1461. DOI: 10.1016/j.watres.2009.10.029

11 M.A. Sabur, A.A. Khan and S. Safiullah, Treatment of textile waste water by coagulation precipitation method, J. Sci. Res., 2012, 4, 623-633. http://dx.doi.org/10.3329/jsr.v4i3.10777

12 S. Papić, N. Koprivanac and A.L. Božic, Removal of reactive dyes from waste water using Fe (III) coagulant, Color. Technol., 2000, 116, 352-358.

DOI: 10.1111/ j.1478-4408.2000.tb00013.x

$13 \mathrm{~N}$. Al-Bastaki, Removal of methyl orange dye and $\mathrm{Na}_{2} \mathrm{SO}_{4}$ salt from synthetic waste water using reverse osmosis, Chem. Eng. Process., 2004, 43, 1561-1567. https://doi.org/10.1016/j.cep.2004.03.001

14 K. M. Nowak and J.K. Skowron, Ceramic membrane behavior in anionic dye removal by ultra-filtration, Desal. Water Treat., 2011, 34 367-373.

DOI: 10/5004/dwt.2011.2806

15 V.K. Gupta, R. Jain, A. Nayak, S. Agarwal and M. Shrivastava, Removal of the hazardous dye Tartrazine by photodegradation on titanium dioxide surface, Mater. Sci. Eng. C, 2011, 31, 1062-1067. https://doi.org/10.1016/j.msec.2011.03.006

16 D. Jager, D. Kupka, M. Vaclavikova, L. Ivanicova and G. Gallios, Degradation of Reactive black 5 by electrochemical oxidation, Chemosphere, 2018, 190, 405-416. https://doi.org/10.1016/j.chemosphere.2017.09.126

17 S. Wijannarong, S. Aroonsrimorakot, P. Thavipoke, C. Kumsopa and S. Sangjan, Removal of reactive dyes from textile dyeing industria effluent by ozonation process, APCBEE procedia, 2013, 5, 279-282. https://doi.org/10.1016/j.apcbee.2013.05.048

18 S. Khamparia and D.K. Jaspal, Adsorption in combination with ozonation for the treatment of textile waste water: a critical review, Front. Environ. Sci. Eng., 2017, 11, 1-18. https://doi.org/10.1007/s11783-017-0899-5

19 Z. Cao, J. Zhang, J. Zhou, X. Ruan, D. Chen, J. Liu, Q. Liu and G. Quin, Electroplating sludge derived zinc-ferrite catalyst for the efficient photofenton degradation of dye, J. Environ. Manage., 2017, 193, 146-153. http://dx.doi.org /10.1016/j.jenvman.2016.11.039

20 S. Carvalho and N. Carvalho, Dye degradation by green heterogeneous fenton catalysts prepared in presence of Camellia sinensis, J. Environ. Manage., 2017, 187, 82-88. http://dx.doi.org/10.1016/j.jenvman.2016.11.032

21 D. Schimmel, K.C. Fagnani, J.B. Oliveira, M.A.S.D. Barros and E.A. da-Silva, Adsorption of Turquoise blue QG reactive dye on commer- cial activated carbon in batch reactor: kinetic and equilibrium studies, Braz. J. Chem. Eng., 2010, 27, 289-298.

http://dx.doi.org/10.1590/S0104-66322010000200007

22 M. Mulugeta and B. Lelisa, Removal of Methylene blue (mb) dye from aqueous solution by bioadsorption onto untreated Parthenium hysterophorus weed, Mod. Chem. Appl., 2014, 2, 1-5. http://dx.doi.org/10.4172/2329-6798.1000146

23 B.H. Hameed, Grass waste: a novel sorbent for the removal of basic dye from aqueous solution, J. Hazard. Mater., 2009, 166, 233-238. DOI: 10.1016/j.jhazmat.2008.11.019

24 S. Bapat and D. Jaspal, Parthenium hysterophorus: novel adsorbent for the removal of heavy metals and dyes, Global J. Environ. Sci. Manage., 2016, 2, 135-144.

DOI: 10.7508/GJESM.2016.02.004

25 A. Bhatnagar and A.K. Minocha, Conventional and non-conventional adsorbents for removal of pollutants from water - a review, Indian J. Chem. Technol., 2006, 13, 203-217.

26 S. Allen and B. Koumanova, Decolorization of water/wastewater using adsorption - a review, J. Univ. Chem. Technol. Metall., 2005, 40, 175-192.

27 N. Sharma, D.P. Tiwari and S.K. Singh, Decolorization of synthetic dyes by agricultural waste - a review, Int. J. Sci. Eng. Res., 2012, 3, 1-10.

28 A. Yaras and H. Arslanoglu, Valorization of paper mill sludge as adsorbent in adsorption process of copper (II) ion from synthetic solution: kinetic, isotherm and thermodynamic studies, Arab. J. Sci. Eng., 2017, 2017, 1-10.

29 L.F. Pintor-Ibarra, J.J. Rivera-Prado, M. Ngangyo-Heya and J.G. Rutiaga-Quinones, Evaluation of the chemical components of Eichhornia crassipes as an alternative raw material for pulp and paper, Bio Resources, 2018, 13, 2800-2813.

30 B. Zhao, W. Xiao, Y. Shang, H. Zhu and R. Han, Adsorption of Light green anionic dye using cationic surfactant-modified peanut husk in batch mode, Arab. J. Chem., 2017, 10, 595-602. https://doi.org/10.1016/j.arabjc.2014.03.010

31 S. Karthikeyan, B. Sivakumar and N. Sivakumar, Film and pore diffusion modeling for adsorption of Reactive red 2 from aqueous solution on to activated carbon prepared from bio-diesel industrial waste, E-J. Chem., 2010, 7, 175-184.

32 G. Boyd, A. Adamson and L. Myers, The exchange adsorption of ions from aqueous solutions by organic zeolites. II kinetics, J. Amer. Chem. Soc., 1947, 69, 2836-2844.

33 G. Crini and P. Badot, Application of chitosan, a natural amino polysaccharide for dye removal from aqueous solution by adsorption processes using batch studies: a review of recent literature, Prog. Polym. Sci., 2007, 33, 399-447.

https://doi.org/10.1016/j. progpolymsci.2007.11.001

34 R. Saadi, Z. Saadi, R. Fazaeli and N.E. Fard, Monolayer and multilayer adsorption isotherm models for sorption from aqueous media, Korean J. Chem. Eng., 2015, 32, 787-799. DOI: $10.1007 / \mathrm{s} 11814-015-0053-7$

35 R. Gusain, N. Kumar, E. Fosso-Kankeu and S.S. Ray, Efficient removal of $\mathrm{Pb}(\mathrm{II})$ and $\mathrm{Cd}(\mathrm{II})$ from industrial mine water by a hierarchical $\mathrm{MoS}_{2}$ /SH-MWCNT nanocomposite, ACS OMEGA, 2019, 2019, 1-14. DOI: 10.1021 /acsomega.9b01603

36 C.R. Kothari, Research Methodology Methods and Techniques, 13, 2nd edn., New Age International Publisher, New Delhi, India, 2004, 233-255, ISBN (13): 978-81-224-2488-1

37 Y. Liu, Reactive Dye Dimerization for Enhanced Affinity to Cotton Fibers, Masters dissertation, North Carolina State University, Raleigh, USA, 2016, 1-106. http://www.lib.ncsu.edu/resolver/1840.16/11367

38 S.Y. Wong, Y.P. Tang, A.H. Abdullah and S.T. Ong, Removal of Basic blue 3 and Reactive orange 16 by adsorption on to quartenized sugar cane bagasse, Malaysian J. Anal. Sci., 2009, 13, 185-193.

39 G.O. El-sayed, M.E. Moustafa and M.F. Mahrous, Removal of Disperse 2B-LN dye from industrial water onto activated carbon prepared from sugar cane stalks, Int. J. Chem. Tech. Res., 2011, 23, 1604-1611.

$40 \mathrm{~K}$. Arzani, A. Ashtiani, G. Behdad and A. Kashi, Equilibrium and kinetic adsorption study of the removal of Orange-G dye using carbon mesoporous material, J. Inorg. Mater., 2012, 27, 660-666. DOI: 10.3724/SP.J.1077.2012.12050 
41 D.D. Do and H.D. Do, Analysis of dual diffusion and nonlinear adsorption isotherm with a time lag method, Adsorption, 2000, 6, 111-123.

https://doi.org/10.1023/A:1008959517075

42 S. Behera, S. Ghanty, F. Ahmad, S. Santra and S. Banerjee, UV-visible spectrophotometric method development and validation of assay of paracetamol tablet formulation, J. Anal. Bioanal. Tech., 2012, 3, $1-6$.

DOI: $10.4172 / 2155-9872.1000151$

43 F. Zamora, E. Sabio, S. Roman, C. Garcia and B. Ledesma, Modelling the adsorption of p-nitrophenol by the Boyd method in conjugation with the finite element method, Dyes Pigments, 74, 590-594. DOI: 10.1016/j.dyepig.2006.03.024

44 Y. Khambhaty, K. Mody, S. Basha and B. Jha, Kinetic, Equilibrium and thermodynamic studies on biosorption of hexavalent chromium by dead fungal biomass of marine Aspergillus niger, Chem. Eng. J., 2009, 145, 489-495.

DOI: 10.1016/j.cej.2008.05.002

45 R. Viegas, M. Campinas, H. Costa and M. Rosa, How do the HSDM and Boyd's model compare for estimating intra particle diffusion coefficients in adsorption processes, Adsorption, 2014, 20, 737-746. https://doi.org/10.1007/s10450-014-9617-9

46 P. Simha, A. Yadav, D. Pinjari and A.B. Pandit, On the behavior, mechanistic modelling and interaction of biochar and crop fertilizers in aqueous solutions, Resource-Efficient Technol., 2016, 2, 133142.

47 F. Falil, F. Allam, B. Gourich, C. Vial and F. Audonnet, Adsorption of Astrazon orange $\mathrm{G}$ onto natural Morroccan phosphate rock: a mechanistic study, J. Environ. Chem. Eng., 2016, 4, 2556-2564. http://dx.doi.org/10.1016/j.jece.2016.04.029 


\section{Supplementary material to:}

S.A. Bapat and D.K. Jaspal,

Surface-modified Water Hyacinth (Eichhornia crassipes) over Activated Carbon for Wastewater Treatment: A Comparative Account,

S. Afr. J. Chem., 2020, 73, 70-80. 


\title{
Surface Modified Water Hyacinth (Eichhornia crassipes) over Activated Carbon for Waste Water Treatment: A Comparative Account
}

\author{
Shreyas A. Bapat ${ }^{a}$, Dipika K. Jaspal ${ }^{\text {b* }}$
}

a Symbiosis Institute of Technology (SIT), Symbiosis International (Deemed University) (SIU), Gram: Lavale, Tal: Mulshi, Pune-412115, Maharashtra, India, shreyasbapat111@gmail.com Tel- +919921353505 ORCID id: https://orcid.org/0000-0001-9403-7178

$\mathbf{b}^{*}$ Symbiosis Institute of Technology (SIT), Symbiosis International (Deemed University) (SIU), Gram: Lavale, Tal: Mulshi, Pune-412115, Maharashtra, India, dipikaj@sitpune.edu.in Tel- +919225635349

ORCID id: https://orcid.org/0000-0002-3532-8626

\section{TABLE OF CONTENTS}

1. Figure S1- $\log (1-\mathrm{F})$ vs. t plot at $27^{\circ} \mathrm{C}$ for treated $\mathrm{WH}$ stem and $\mathrm{AC}$ adsorbents

2. Figure S2- $\log (1-\mathrm{F})$ vs. t plot at $40^{\circ} \mathrm{C}$ for treated $\mathrm{WH}$ stem and $\mathrm{AC}$ adsorbents

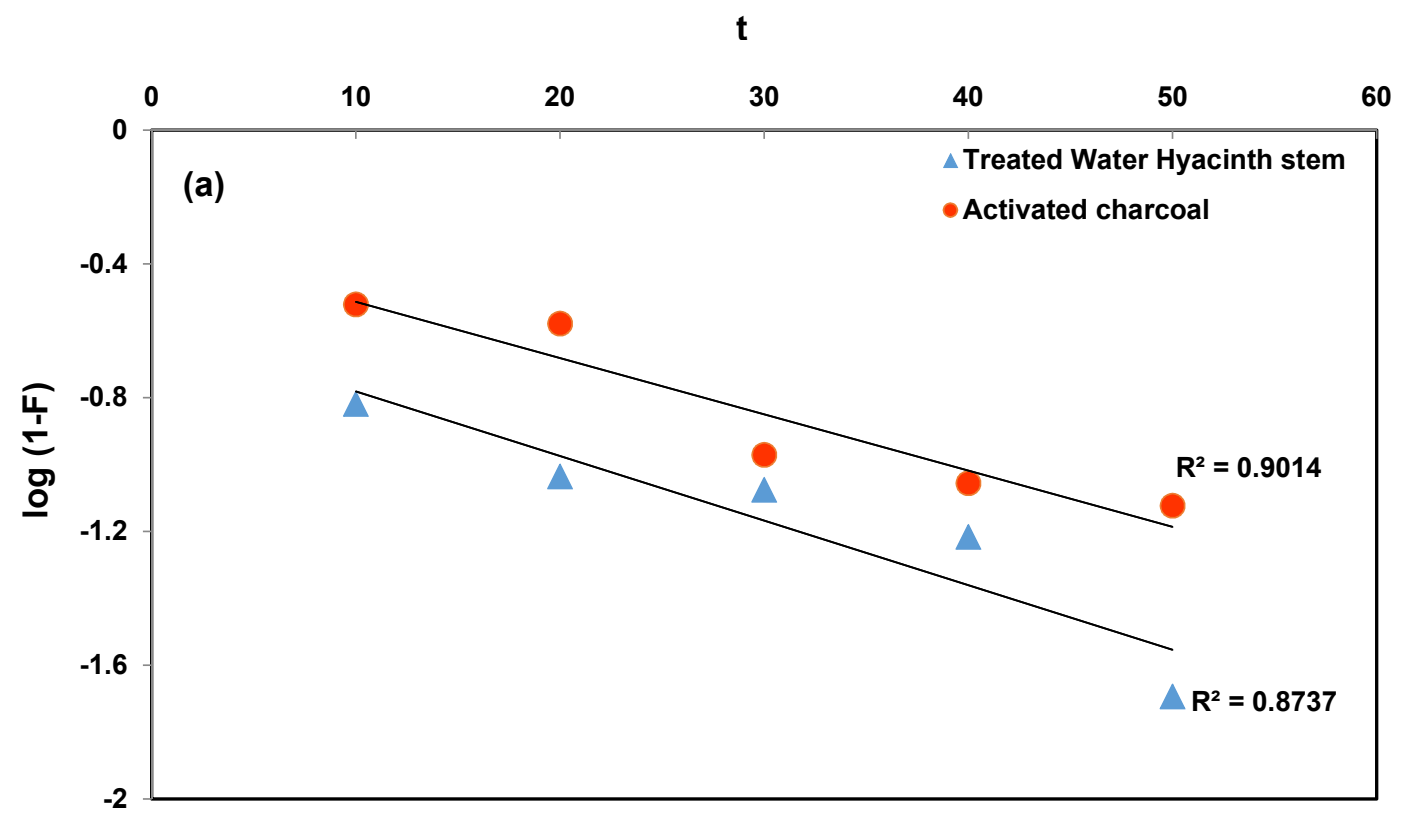

Fig. S1 $\log (1-\mathrm{F})$ vs. $\mathrm{t}$ plot at $27^{\circ} \mathrm{C}$ for treated $\mathrm{WH}$ stem and $\mathrm{AC}$ adsorbents 


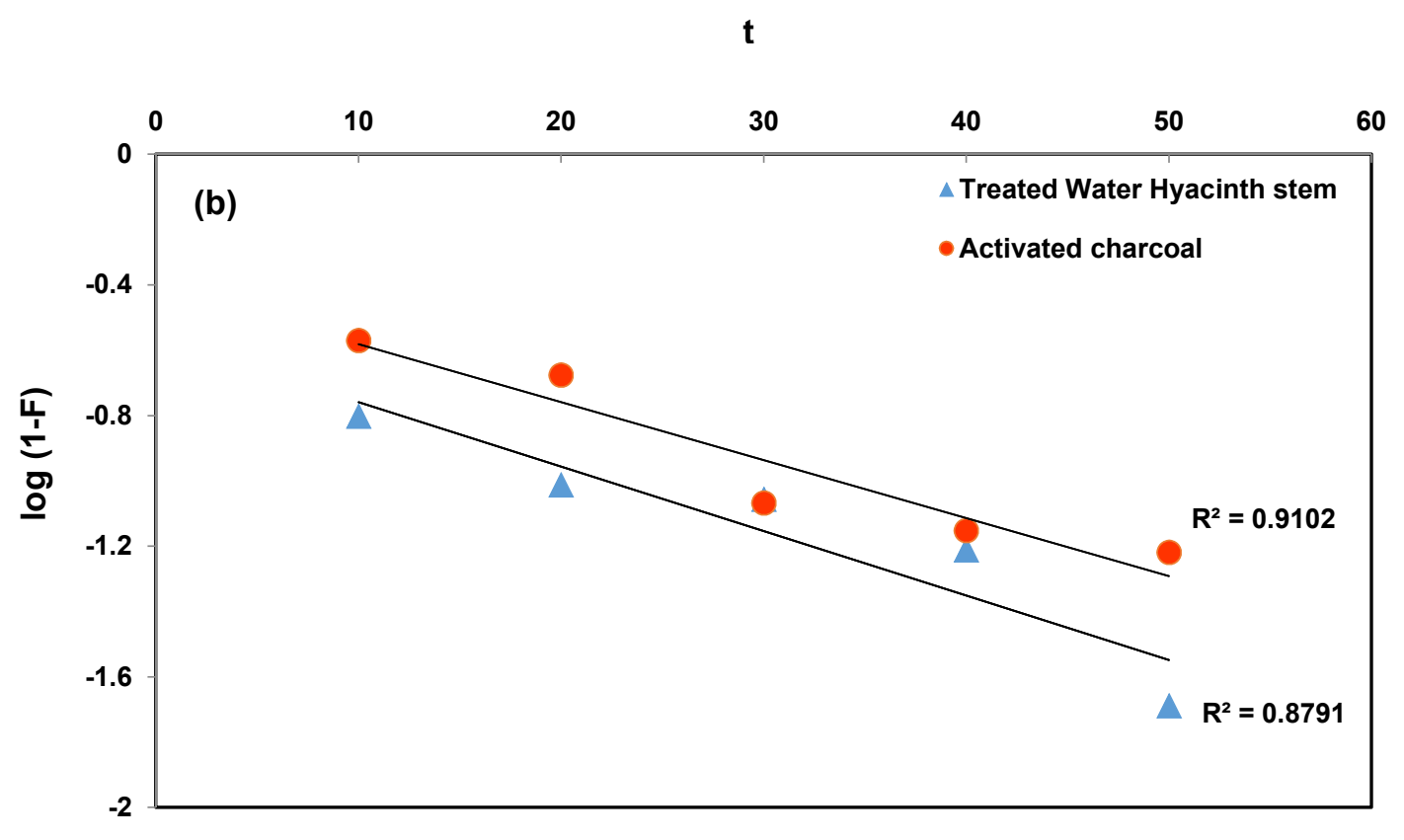

Fig. S2 $\log (1-\mathrm{F})$ vs. t plot at $40^{\circ} \mathrm{C}$ for treated $\mathrm{WH}$ stem and $\mathrm{AC}$ adsorbents 